\title{
Teoria da ação comunicativa de Habermas: Possibilidades de uma ação educativa de cu- nho interdisciplinar na escola
}

\author{
Maria Augusta Salin Gonçalves*
}

\begin{abstract}
RESUMO: O objetivo deste artigo é apresentar e discutir condições teórico-práticas da execução de um projeto de ação educativa de cunho interdisciplinar na escola, tendo como base a teoria da ação comunicativa de Jürgen Habermas. Inicialmente, apresentamos aspectos significativos dessa teoria. A seguir, apresentamos linhas norteadoras que adotamos como ponto de partida e suporte da pesquisa-ação, e que fornecem também as categorias para análise e interpretação da experiência.
\end{abstract}

Palavras-chave: Interdisciplinaridade, teoria da ação comunicativa, comunicação, linguagem

Pode-se afirmar que, de maneira geral, é grande a preocupação dos educadores com a atomização do conhecimento existente nos currículos escolares, que produz uma visão fragmentada do real, desvinculada de um contexto histórico e distanciada da realidade na qual o aluno vive. Educadores, sociólogos e epistemólogos têm analisado essa questão sob diferentes perspectivas e trazido importantes contribuições no que diz respeito à interdisciplinaridade, visualizando-a como uma possibilidade de superação dessa fragmentação do conhecimento, tanto em nível de currículo como de pesquisa (Etges 1993; Fazenda 1991 e 1994; Freitas 1989; Frigotto 1993; Jantsch e Bianchetti 1995; Japiassu 1976; Lück 1994; Severino 1995; Siebeneichler 1989; entre outros).

Neste artigo, pretendo abordar essa questão na perspectiva do currículo na escola básica, cujos objetivos são anunciados no sentido de for-

\footnotetext{
* Professora do Programa de Mestrado em Educação da Universidade do Vale do Rio dos Sinos - Unisinos.
} 
mar cidadãos que participem ativa e criticamente do processo cultural de sua época histórica. Parece-me pertinente colocar aqui a questão: Como possibilitar ao aluno condições de participação ativa e crítica, em uma estrutura escolar que em si mesma é fragmentada e destituída de vinculação com a vida concreta e com os problemas de sua época histórica?

Por outro lado, essa estrutura curricular gera um isolamento entre os professores, ficando cada um fechado na sua disciplina, pouco comunicando-se com os colegas a respeito dos problemas educacionais em geral e dos relativos aos seus alunos em particular.

Não pretendo, neste artigo, deter-me na crítica à escola dividida em diferentes disciplinas com programas específicos e conteúdos determinados desde cima, mas, sim, refletir sobre as possibilidades de, dentro das condições atuais de ensino, minorar as conseqüências da fragmentação dos currículos escolares e das condições de isolamento do professor.

Com o objetivo de buscar uma alternativa para maior integração da prática educativa, apresento algumas reflexões sobre as possibilidades de uma ação educativa de cunho interdisciplinar na escola, apontando fundamentos teórico-práticos que dêem suporte a essa ação e, ao mesmo tempo, forneçam as categorias para a análise e a avaliação.

Para fundamentar uma ação educativa de cunho interdisciplinar, encontramos idéias norteadoras na teoria da ação comunicativa de Jürgen Habermas, que passarei a abordar em primeiro lugar, destacando os aspectos mais significativos para nossa proposta. Finalizando, procuro refletir sobre algumas questões básicas relacionadas à realização de um projeto de ação interdisciplinar na Escola, discutindo os seus fundamentos com base na teoria da ação comunicativa.

Esta proposta não pretende se constituir em uma aplicação mecânica da teoria da ação comunicativa de Habermas em uma situação empírica da área pedagógica. A minha intenção é buscar, nessa teoria, subsídios para fundamentar e orientar uma ação interdisciplinar que tenha como como base uma interação dialógica, sem perder, no entanto, a vinculação com a totalidade do pensamento desse autor.

\section{Teoria da ação comunicativa}

Jürgen Habermas (1929) é um filósofo e sociólogo alemão contemporâneo, que tem seu nome associado à Teoria Crítica da Escola de Frank- 
furt, cujos principais representantes são Adorno (1903-1969), Marcuse (1898-1979), Horkheimer (1895-1973) e Benjamin (1892-1940). Não obstante as diferenças de pensamento desses filósofos, um tema perpassa a obra de todos eles: a crítica radical à sociedade industrial moderna.

Com o processo de modernização passou a prevalecer nas sociedades industriais uma forma de racionalidade: a racionalidade instrumental. Essa racionalidade define-se pela relação meios-fins, ou seja, pela organização de meios adequados para atingir determinados fins ou pela escolha entre alternativas estratégicas com vistas à consecução de objetivos.

Habermas partilha dessa crítica. Não permanece, no entanto, no momento da negatividade, mas tenta salvar a razão da perplexidade e do pessimismo. Ao repensar a idéia de razão e racionalização, Habermas busca superar as oposições que transpassam a cultura contemporânea, que, como resume McCarthy, são: "modernidade versus pós-modernidade, racionalismo versus relativismo, universalismo versus contextualismo, subjetivismo versus objetivismo, humanismo versus 'morte do homem', etc." (1996, p.10).

Habermas busca superar o conceito de racionalidade instrumental, ampliando o conceito de razão, para o de uma razão que contém em si as possibilidades de reconciliação consigo mesma: a razão comunicativa. Discutiremos a seguir esses dois conceitos básicos no pensamento de Habermas.

\section{Racionalidade instrumental e}

\section{racionalidade comunicativa}

Em suas análises a respeito da sociedade capitalista moderna, Max Weber (1864-1920) introduz o conceito de "racionalização" para descrever o processo de desenvolvimento existente nas sociedades modernas. Esse processo caracteriza-se pela ampliação crescente de esferas sociais que ficam submetidas a critérios técnicos de decisão racional, isto é, a critérios de adequação e organização de meios em relação a determinados fins, como, por exemplo, acontece na urbanização das formas de existência, na tecnificação do tráfego e da comunicação. O planejamento e o cálculo foram tornando-se, cada vez mais, partes integrantes de procedimentos envolvendo questões administrativas. 
A transformação pela qual passaram as sociedades industriais nesse processo de modernização, ou seja, de racionalização da ação social, está diretamente associada às formas de desenvolvimento do trabalho industrial na sociedade capitalista, que expandiram os procedimentos e a racionalidade a eles inerente para outros setores do âmbito da vida social. O desenvolvimento industrial, por sua vez, está estreitamente vinculado ao progresso da ciência e da técnica.

Em suas análises, Max Weber, Adorno e Horkheimer (1986) e, mais tarde, Marcuse (1982) fazem uma crítica radical à racionalidade científica, que, entendida como neutra em relação a valores, afastou do exame da razão, como subjetivas e irracionais, todas as questões sociais que não podiam ser resolvidas na perspectiva da relação meio-fins, e que fugiam do âmbito das questões relativas à economia e à eficácia dos meios.

Para esses autores, a ciência e a técnica, ao visarem o domínio da natureza e a sua submissão ao homem, já trazem em si o germe da dominação. Abstraindo de toda a discussão em torno da questão de valores, esse tipo de racionalidade traz em seu bojo uma forma de dominação política que não lhe é imposta de fora, mas habita o seu interior, e já está presente no processo de sua própria construção.

Habermas não se posiciona radicalmente contra a racionalidade instrumental da ciência e da técnica em si mesmas, na medida em que essas contribuem para a autoconservação do homem. Habermas considera que o trabalho, pela sua essência de dominar a natureza para pô-la a serviço do homem, possui uma racionalidade do mesmo tipo da racionalidade da ciência e da técnica, isto é, uma racionalidade que consiste na organização e na escolha adequada de meios para atingir determinados fins (1987d).

Para ele, a ciência e a técnica ampliam as possibilidades humanas, libertando o homem do jugo das necessidades materiais, sendo o desenvolvimento da espécie humana resultado de um processo histórico de desenvolvimento tecnológico, institucional e cultural, processos que são interdependentes.

Habermas posiciona-se radicalmente contra a universalização da ciência e da técnica, isto é, contra a penetração da racionalidade científica, instrumental, em esferas de decisão onde deveria imperar um outro tipo de racionalidade: a racionalidade comunicativa. 
Ao examinar essa questão, Habermas (1987d) distingue dois âmbitos do agir humano contidos no conceito de Marx de "atividade humana sensível", que são interdependentes, mas que podem ser analisados separadamente: o trabalho e a interação social. Por "trabalho" ou "ação racional teleológica", Habermas entende o processo pelo qual o homem emancipa-se progressivamente da natureza. Por "interação", Habermas entende a esfera da sociedade em que normas sociais se constituem a partir da convivência entre sujeitos, capazes de comunicação e ação. Nessa dimensão da prática social, prevalece uma ação comunicativa, isto é, "uma interação simbolicamente mediada", a qual se orienta "segundo normas de vigência obrigatória que definem as expectativas recíprocas de comportamento e que têm de ser entendidas e reconhecidas, pelo menos, por dois sujeitos agentes" (1987d, p. 57).

$\mathrm{Na}$ moderna sociedade industrial, esses dois âmbitos da prática social sofreram grandes transformações, que estão na raiz dos inúmeros problemas com que nos defrontamos na época atual.

O desenvolvimento do conhecimento científico e técnico, ao propiciar o crescimento e o aperfeiçoamento das forças produtivas, provê o sistema capitalista de um mecanismo regular que assegura a sua manutenção. Desta forma, "se institucionaliza a introdução de novas tecnologias e de novas estratégias", isto é, "institucionaliza-se a inovação enquanto tal", cumprindo a ciência e a técnica o papel de legitimar a dominação (Habermas 1987d, p. 62).

Com o crescimento das forças produtivas, modificaram-se as atribuições do Estado. A empresa passou, de forma crescente, a intervir no planejamento da vida econômica, direcionando decisões que anteriormente cabiam à esfera social, e assumindo atribuições que eram tradicionalmente da competência dos aparelhos do Estado. Este, por sua vez, passou a intervir diretamente na economia, assumindo, no capitalismo contemporâneo, a função de preservar as relações de produção, submetendo-se às determinações do capital global, com o qual busca conciliar os interesses nacionais.

Procurando compensar as disfunções do sistema capitalista, as sociedades industriais desenvolvidas adotaram o Estado de Bem-estar, que busca proporcionar à população condições de educação, saúde, habitação e trabalho. Promovendo à população segurança social e oportunidades de promoção pessoal, esse programa estatal pretende garantir, ao mesmo tempo, "a forma privada de revalorização do capital" (1987d, p. 70). 
A esfera política, passando a orientar-se para a prevenção das disfuncionalidades do sistema, se enfraquece em sua função de ser espaço de discussão a respeito da realização de fins éticos de convivência social, atendendo a interesses coletivos. A política passou dessa forma a ocupar-se mais com a solução de problemas técnicos do que com questões que dizem respeito à interação social e cuja busca de soluções envolve o diálogo, tais como justiça, liberdade, poder, opressão, satisfação, violência, etc.

O Estado contemporâneo está cada vez mais submetido aos mecanismos financeiros, ocupando-se de forma crescente com questões de ordem técnica, perdendo as instituições, como, por exemplo, o direito, a economia e a política, ao longo desse processo, a ligação com os fins para os quais foram criadas. Temos, assim, um Estado que, por um lado, se vê subtraído de parte de suas funções sociais primordiais e, por outro, na ampliação crescente de subsistemas de "ação racional com respeito a fins", se vê submerso numa administração burocrática que, imbuída de uma racionalidade instrumental, pretende dotá-lo de eficácia na gestão dos problemas sociais.

$\mathrm{Na}$ medida em que a racionalidade instrumental da ciência e da técnica penetra nas esferas institucionais da sociedade, transforma as próprias instituições, de tal modo que as questões referentes às decisões racionais baseadas em valores, ou seja, em necessidades sociais e interesses globais, que se situam no plano da interação, são afastadas do âmbito da reflexão e da discussão. A racionalidade instrumental, na trajetória de ampliação de seu campo de atuação, substituiu de forma crescente o espaço da interação comunicativa que havia anteriormente no âmbito das decisões práticas que diziam respeito à comunidade. Dessa forma, caem por terra as antigas formas ideológicas de legitimação das relações sociais de poder. Com esse tipo de racionalidade não se questiona se as normas institucionais vigentes são justas ou não, mas somente se são eficazes, isto é, se os meios são adequados aos fins propostos, ficando a questão dos valores éticos e políticos submetida a interesses instrumentais e reduzida à discussão de problemas técnicos.

A causa dos graves problemas da sociedade industrial moderna, para Habermas, não reside no desenvolvimento científico e tecnológico como tal, mas, sim, na unilateralidade dessa perspectiva como projeto humano, que deixa de lado a discussão sobre questões vitais em torno das quais uma sociedade decide o rumo da sua história.

A subjetividade do indivíduo não é construída através de um ato solitário de auto-reflexão, mas, sim, é resultante de um processo de formação 
que se dá em uma complexa rede de interações. A interação social é, ao menos potencialmente, uma interação dialógica, comunicativa. A penetração da racionalidade instrumental no âmbito da ação humana interativa, ao produzir um esvaziamento da ação comunicativa e ao reduzi-la à sua própria estrutura de ação, gerou, no homem contemporâneo, formas de sentir, pensar e agir - fundadas no individualismo, no isolamento, na competição, no cálculo e no rendimento -, que estão na base dos problemas sociais.

Como uma possibilidade de transformação da sociedade contemporânea na busca de solução para os graves problemas que assolam a humanidade, Habermas visualiza o resgate de uma racionalidade comunicativa em esferas de decisão do âmbito da interação social que foram penetradas por uma racionalidade instrumental.

Tendo em vista que o homem não reage simplesmente a estímulos do meio, mas atribui um sentido às suas ações e, graças à linguagem, é capaz de comunicar percepções e desejos, intenções, expectativas e pensamentos, Habermas vislumbra a possibilidade de que, através do diálogo, o homem possa retomar o seu papel de sujeito.

A sociedade brasileira vive um momento de profunda crise. A ideologia do neoliberalismo, desencarregando o Estado da sua responsabilidade social, e a rápida capitalização externa do país trazem consigo inúmeros custos sociais. Convivemos diariamente com a violência, a miséria e o desemprego, e, muitas vezes, um sentimento de perplexidade e impotência nos invade.

As condições sociais, no entanto, não são estáticas nem imutáveis, pois são o resultado de um processo histórico.

Como educadores precisamos acreditar em possibilidades de mudança, e, no âmbito de nossa ação profissional, tentar abrir espaços para a emergência de uma nova racionalidade, que favoreça a reconstrução da sociedade e a reinvenção da cultura. Esse processo somente será viável no desenvolvimento de uma ética de responsabilidade social, que embase ações que visem ao bem coletivo, isto é, que tenham por objetivo a criação de possibilidades de vida a todos, incluindo as gerações futuras.

Nessa perspectiva, a escola apresenta-se como o espaço onde uma ação comunicativa, ao ser desenvolvida sistematicamente, coincide com os objetivos de uma educação que visa à formação de indivíduos críticos e participativos. 


\section{Ação comunicativa}

Com sua teoria, Habermas pretende mostrar que as idéias de verdade, liberdade e justiça inscrevem-se de forma quase transcendental nas estruturas da fala cotidiana (Horster 1988).

As comunicações que os sujeitos estabelecem entre si, mediadas por atos de fala, dizem respeito sempre a três mundos: o mundo objetivo das coisas, o mundo social das normas e instituições e o mundo subjetivo das vivências e dos sentimentos. As relações com esses três mundos estão presentes, ainda que não na mesma medida, em todas as interações sociais.

Em primeiro lugar, as pessoas, ao interagirem, coordenam suas ações. Do conhecimento que elas partilham do mundo objetivo depende o sucesso ou o insucesso de suas ações conjuntas, sendo que a violação das regras técnicas conduz ao fracasso. Em segundo lugar, as pessoas interagem orientando-se segundo normas sociais que já existem previamente ou que são produzidas durante a interação. Essas normas definem expectativas recíprocas de comportamento, sobre as quais todos os participantes têm conhecimento. Esse tipo de ação não é avaliada pelo seu êxito, mas pelo reconhecimento intersubjetivo e pelo consenso valorativo, sendo que sua violação gera sanções. Em terceiro lugar, em todas as interações as pessoas revelam algo de suas vivências, intenções, necessidades, de seus temores etc., de tal modo que deixam transparecer sua interioridade. Embora as pessoas, em maior ou menor grau, possam controlar as manifestações de suas vivências subjetivas, das suas ações podem-se tirar conclusões a respeito da sua veracidade.

A cada um desses mundos correspondem diferentes pretensões de validade. Ao mundo objetivo correspondem pretensões de validade referentes à verdade das afirmações feitas pelos participantes no processo comunicativo. Ao mundo social correspondem pretensões de validade referentes à correção e à adequação das normas, e ao mundo subjetivo - das vivências e sentimentos - correspondem pretensões de veracidade, o que significa que os participantes do diálogo estejam sendo sinceros na expressão dos seus sentimentos.

No que diz respeito tanto à coordenação de ações, como às avaliações éticas e às manifestações subjetivas, a linguagem ocupa 
um papel fundamental. A legitimação dos valores - verdade, correção normativa e veracidade -, que toda a ação comunicativa pressupõe, não é alcançada por uma racionalidade meio-fim, mas somente pela argumentação em função de princípios reconhecidos e validados pelo grupo.

Habermas propõe um modelo ideal de ação comunicativa, em que as pessoas interagem e, através da utilização da linguagem, organizam-se socialmente, buscando o consenso de uma forma livre de toda a coação externa e interna.

Vinculado ao modelo da ação comunicativa, Habermas apresenta a situação lingüística ideal: o discurso. Para Habermas, discurso (Diskurs) refere-se a uma das formas da comunicação ou da "fala" (Rede), que tem por objetivo fundamentar as pretensões de validade das opiniões e normas em que se baseia implicitamente a outra forma de comunicação ou "fala", que chama de "agir comunicativo" ou "interação". O discurso - teórico ou prático, conforme se refira a pretensões de validade de opiniões ou de normas sociais - no sentido de Habermas possui um aspecto intersubjetivo, que serve para classificá-lo como uma espécie do gênero "comunicação", e um lógicoargumentativo, que serve para determiná-lo como caso específico da fundamentação de pretensões de validade problematizadas (Almeida 1989).

Assim como o modelo de comunicação ideal constitui-se na utopia de um processo de comunicação e remete a uma ordem social ainda não existente, a situação lingüística ideal constitui-se no telos de um discurso, que seria perfeito se existissem condições ideais de realização (Freitag 1980). Sendo assim, esses dois modelos se constituem em utopias, que todavia devem ser pressupostas como reais, para que possa se efetivar qualquer comunicação. Ao mesmo tempo, esses modelos fornecem os elementos para uma crítica das formas concretas de interação e discurso, constituindo-se em uma antecipação dessas.

O processo de comunicação que visa ao entendimento mútuo está na base de toda a interação, pois somente uma argumentação em forma de discurso permite o acordo de indivíduos quanto à validade das proposições ou à legitimidade das normas. Por outro lado, o discurso pressupõe a interação, isto é, a participação de atores que se comunicam livremente e em situação de simetria. 


\title{
Possibilidades educacionais da ação comunicativa em um projeto de ação interdisciplinar
}

A teoria da ação comunicativa de Habermas tem sido, sob diferentes perspectivas, fonte inspiradora de reflexões em torno de questões educativas (Schäfer 1982; Pucci et alii. 1994; Freitag 1986; Flecha 1996; Peukert 1996; Prestes 1996; entre outros).

Neste item, pretendo tecer algumas considerações a respeito das possibilidades de a teoria da ação comunicativa de Habermas oferecer idéias norteadoras para a realização de um projeto interdisciplinar na Escola, na medida em que fornece as bases para uma comunicação que visa ao entendimento mútuo.

Tratando-se de um projeto pedagógico, creio que é oportuno anteriormente explicitar os conceitos de educação e interdisciplinaridade que embasam as nossas reflexões e nossas ações pedagógicas. Penso a educação

\begin{abstract}
(...) como uma instituição social e histórica, que tem como fim gerar transformações tanto em nível das consciências individuais, como em nível mais amplo, da sociedade. Trazendo em seu bojo a concepção do homem na dimensão da práxis - como um ser capaz de refletir sobre a realidade e nela atuar, ao mesmo tempo que esta atua sobre ele transformando-o -, a Educação é vista aqui como uma possibilidade, ainda que limitada por condicionantes históricos (e justamente o desvelamento desses condicionantes históricos é que possibilita o pensamento de transformação), de uma ação transformadora, buscando modificar as condições desumanizantes da sociedade industrial contemporânea e, em especial, da sociedade brasileira. (Gonçalves 1996, p. 170)
\end{abstract}

Em meu livro "Sentir, pensar, agir - Corporeidade e educação (1994, 1997), embora não me aprofunde na teoria de Habermas, já assinalo, na proposta dessa teoria de recuperação da ação comunicativa no âmbito das decisões político-culturais, o seu valor pedagógico, de se constituir em base de fundamentação para a definição de "objetivos educacionais que situam a capacidade de diálogo no centro das decisões comunitárias" (p. 131). 
Em estreita relação de interdependência com os objetivos educativos de formação de cidadãos críticos e participativos estão os objetivos diretamente ligados ao exercício do diálogo e ao desenvolvimento da competência comunicativa.

A proposta de ação educativa de cunho interdisciplinar na escola, que pretendemos desenvolver em uma pesquisa-ação, tem como base um processo de interação comunicativa, em que os professores buscam conjuntamente coordenar e justificar ações pedagógicas, a partir da troca de conhecimentos e enfoques, inerentes a cada disciplina, partilhando e planejando experiências integradas.

Nesse contexto, uma ação educativa de cunho interdisciplinar se constitui no esforço conjunto de professores de uma série do currículo escolar no sentido de estabelecer diálogo na busca de um eixo de articulação entre suas disciplinas, de modo a possibilitar aos alunos experiências em que eles possam integrar os diferentes enfoques disciplinares, enriquecendo sua compreensão da realidade concreta.

Para a consecução dessa ação, em primeiro lugar me parece necessário que os professores cheguem a um consenso a respeito das regras que vão reger as discussões e as participações dos elementos do grupo, fundamentando e justificando essas regras.

Para que os participantes alcancem um consenso verdadeiro, é também fundamental que cheguem a um entendimento sobre questões de cunho filosófico e pedagógico, que estão na base de uma ação comunicativa de cunho interdisciplinar. Essas questões referem-se, primeiramente, a concepções de educação e conhecimento. Pensamos que seja impossível chegar a um consenso real, se os participantes não partilharem de concepções básicas comuns, ou se ao menos não tiverem claramente explicitadas as concepções de todos.

Estabelecidas as regras de discussão e argumentação, essas poderão ser modificadas, no decorrer das sessões, por decisão do grupo. Um processo de ação comunicativa deve ter em seu bojo um princípio de não-dominação, na medida em que se buscam a participação de todos os elementos do grupo e o consenso em relação às próprias regras que vão orientar as discussões.

Para que o entendimento funcione como mecanismo coordenador da ação, é necessário que os participantes na interação ponham-se de acordo acerca da validade que pretendem para suas emissões ou mani- 
festações, isto é, que reconheçam intersubjetivamente as pretensões de validade com que se apresentam diante dos outros. Essas pretensões de validade podem ser reconhecidas ou questionadas (Habermas 1987b).

As três pretensões de validade que 0 ator tem que colocar explicitamente com sua manifestação, conforme já anunciamos anteriormente, são:

- que o enunciado seja verdadeiro (verdade);

- que a manifestação seja correta em relação ao sistema de normas vigente ou que o próprio contexto normativo seja legítimo (legitimidade ou retidão);

- que a intenção expressa coincida com a intenção do falante (veracidade).

O consenso, ou seja, o acordo alcançado comunicativamente, se busca simultaneamente nos três planos e se mede por essas três pretensões de validade suscetíveis de crítica. Quem rejeita a oferta feita com um ato de fala que foi entendido questiona pelo menos uma dessas três pretensões.

Com base nas pretensões de validade, nas reuniões do grupo interdisciplinar, os participantes, ao tentarem se aproximar da situação ideal da fala, deverão reunir esforços no sentido de preencher as seguintes condições:

1. Todos os participantes das discussões têm a mesma chance de se comunicar por meio de atos da fala, argumentando, questionando e respondendo às questões.

2. Todos os participantes têm a mesma chance de apresentar interpretações, opiniões, recomendações, declarações e justificativas e de problematizar sua validade, fundamentar ou rebater (Widerlegen), de tal modo que nenhuma idéia preconcebida (Vormeinung) seja ignorada na continuidade da tematização.

3. Todos os participantes têm a mesma chance de expressar atitudes, sentimentos e desejos referentes à sua subjetividade, devendo ser verdadeiros nas suas manifestações, significando que assim se colocam perante si mesmos e deixam transparecer sua interioridade.

4. Os participantes das discussões têm a mesma chance de empregar atos regulativos, isto é, ordenar e rebelar-se, permitir ou proibir, 
prometer e aceitar promessas, dar explicações e solicitá-las. As expectativas de comportamento são recíprocas e os privilégios, afastados (Horster 1988).

Com o modelo de ação comunicativa de Habermas, como base para uma ação interdisciplinar, pressupõe-se que os participantes na interação intencionalmente mobilizem o potencial de racionalidade que encerram as três relações do sujeito agente com o mundo, com o propósito de chegarem a um entendimento.

Definidos e estabelecidos em consenso as regras de participação e os conceitos básicos para a construção dos fazeres pedagógicos, em um segundo momento a ação educativa de cunho interdisciplinar consiste de sessões de comunicação e diálogo, nas quais o esforço coletivo do grupo se concentra no sentido de buscar eixos articuladores entre as disciplinas do currículo.

O objetivo das discussões, neste momento, é encontrar caminhos comuns e devidamente articulados, para proporcionar aos alunos experiências que lhes possibilitem construir conhecimentos vinculados à sua vida concreta e que lhes permitam uma visão crítica da realidade onde estão inseridos, e, ao mesmo tempo, incentivem sentimentos e pensamentos relacionados a uma participação ativa nos assuntos comunitários, dentro de princípios éticos de cooperação e justiça social.

A direção do processo interativo emerge do próprio grupo e não está sujeita a convenções predeterminadas, exigindo o esforço de todos no sentido de preencher os princípios de realização de uma ação comunicativa com as suas pretensões de validade, e de buscar uma comunicação simétrica, cada vez mais livre e isenta de coação. Esse esforço tem em seu cerne um princípio ético que se concretiza em um processo comunicativo no qual cada elemento do grupo é considerado um parceiro de diálogo, cujas falas são oferecidas à interpretação dos outros, ao mesmo tempo em que ele abre possibilidades para criticar as próprias interpretações.

Dessa forma, o desenrolar do processo é imprevisível, pois a busca de um possível consenso constitui-se em algo inovador para todos os participantes. No momento, somente podemos apontar linhas norteadoras, a partir das pretensões de validade inerentes a uma ação comunicativa. Os princípios e as normas que vão reger essa ação no grupo de professores e fornecer os critérios para avaliações e redimensionamentos vão 
emergir do processo interativo e serão resultados das discussões do grupo, realizadas visando a um consenso.

A análise do desenvolvimento desse processo conta com categorias dos atos de fala, que possibilitam uma compreensão, na perspectiva da teoria da ação comunicativa de Habermas, do processo interativo e argumentativo que se manifesta nesses atos. Para o desenvolvimento da competência comunicativa, na realização da pesquisa, pretendemos atuar no sentido de tentar elevar o nível de argumentação dos participantes. De forma coerente com essa teoria, a pesquisa é realizada com a participação efetiva do grupo de professores participantes da ação interdisciplinar, não somente no direcionamento do processo, mas também na interpretação e na avaliação do seu desenvolvimento.

\title{
Habermas' theory of communicative action: possibilities of interdisciplinary educational action at school
}

\begin{abstract}
The purpose of this article is to present and discuss theoretical and practical conditions for the implementation of a project of interdisciplinary educational action at school, based on Jürgen Habermas' theory of communicative action. Initially we present significant aspects of this theory. Next, we present guidelines that we adopt as point of departure and support of the research, and which also supply the categories for analysis and interpretation of the experience.
\end{abstract}

\section{Bibliografia}

ADORNO, T. e HORKHEIMER, M. Dialética do esclarecimento. Rio de Janeiro: Zahar, 1986.

ALMEIDA, Guido. Nota preliminar do tradutor. In: Consciência moral e agir comunicativo. Rio de Janeiro: Tempo Brasileiro, 1989.

ETGES, Norberto. Produção do conhecimento e interdisciplinaridade. Educação e Realidade № 2, Porto Alegre, v. 18, jul./dez. 1993.

FAZENDA, Ivani Arantes (org.). Práticas interdisciplinares na escola. São Paulo: Cortez, 1991. 
. Interdisciplinaridade: História, teoria e pesquisa. Campinas: Papirus, 1994.

FLECHA, Ramón. As novas desigualdades educativas. In: Novas perspectivas críticas em Educação. Porto Alegre: Artes Médicas, 1996.

FREITAG, Barbara. A teoria crítica: Ontem e hoje. São Paulo: Brasiliense, 1986.

FREITAG, Barbara e ROUANET, Sergio Paulo. Habermas - Sociologia. São Paulo: Ática, 1980.

FREITAS, Luiz C. A questão da interdisciplinaridade: Notas para a reformulação dos cursos de pedagogia. Educação \& Sociedade no 33, São Paulo, 1989.

FRIGOTTO, Gaudêncio. A interdisciplinaridade como necessidade e como problema das ciências sociais. Educação e Realidade ํㅡㄴ 2. Porto Alegre, jul./dez. 1993, v.18.

GONÇALVES, Maria Augusta Salin. Interdisciplinaridade e educação básica: Algumas reflexões introdutórias. In: Educação Básica e o básico em educação. Porto Alegre: Sulina, 1996.

. Sentir, pensar, agir - Corporeidade e educação. $2^{a}$ ed. Campinas: Papirus, 1997.

HABERMAS, Jürgen. Dialética e Hermenêutica - para a crítica da hermenêutica de Gadamer. Porto Alegre: L\&PM, 1987a.

. Teoria de la acción comunicativa I - Racionalidad de la acción y racionalización social. Madri: Taurus, 1987b.

- Teoria de la acción comunicativa II - Crítica de la razón funcionalista. Madri: Taurus, 1987c.

. Técnica e ciência como ideologia. Lisboa: Edições 70, 1987d.

Para o uso pragmático, ético e moral da razão prática. In: Revista de Estudos Avançados da USP o 7. São Paulo, v. 3, set./ dez. 1989, pp. 4-19.

. Consciência moral e agir comunicativo. Rio de Janeiro: Tempo Brasileiro, 1989.

. Teoria de la acción comunicativa: Complementos y estudios previos. Madri: Catedra, 1994. 
HORSTER, Detlef et alii. Habermas zur Einführung. Hamburg: Soak, 1988.

JANTSCH, Ari P. e BIANCHETTI, Lucídio. Interdisciplinaridade - Para além da filosofia do sujeito. Petrópolis: Vozes, 1995.

JAPIASSU, Hilton. Interdisciplinaridade e patologia do saber. Rio de Janeiro: Imago, 1976.

LÜCK, Heloísa. Pedagogia interdisciplinar: Fundamentos teóricometodológicos. Petrópolis: Vozes, 1994.

MARCUSE, Herbert. A ideologia da sociedade industrial - O homem unidimensional. Rio de Janeiro: Zahar, 1982.

MCCARTHY, Thomas. La teoría crítica de Jürgen Habermas. Madri: Tecnos, 1995.

PEUKERT, Helmut. Problemas básicos de uma teoria crítica da educação. Educação \& Sociedade no 56. Campinas: Cedes/Papirus, 1996, pp. 412-430.

PRESTES, Nadja M. Hermann. Educação e racionalidade: Conexões e possibilidades de uma razão comunicativa na escola. Porto Alegre: Edipucrs, 1996.

PUCCI, Bruno et alii. Teoria crítica e educação - A questão cultural na Escola de Frankfurt. Petrópolis: Vozes, 1994.

SCHÄFER, Karl H. e SCHALLER, Klaus. Ciência educadora crítica e didática comunicativa. Rio de Janeiro: Tempo Brasileiro, 1982.

SEVERINO, Antonio Joaquim. O uno e o múltiplo: O sentido antropológico do interdisciplinar. In: Jantsch e Bianchetti, Interdisciplinaridade para além da filosofia do sujeito. Petrópolis: Vozes, 1995.

SIEBENEICHLER, Flavio. Encontros e desencontros no caminho da interdisciplinaridade: G. Gusdorf e J. Habermas. Revista Tempo Brasileiro 98. Rio de Janeiro, jul./set. 1989. 